\title{
Optimizing processing parameters for hybridized kenaf/PALF reinforced HDPE composite
}

\begin{abstract}
This work is aimed at achieving optimum processing parameters for Kenaf/PALF/HDPE. Processing parameters like temperature, speed of rotor and duration of composite mixing in an internal mixer were examined. Oven conditioned and unconditioned specimen were prepared and tested. The best tensile strength and tensile modulus were obtained at an optimum processing parameters of $190^{\circ} \mathrm{C}, 40 \mathrm{rpm}$, and $15 \mathrm{~min}$ for temperature of processing, speed of rotor and duration of mixing respectively, while $190^{\circ} \mathrm{C}, 40 \mathrm{rpm}$ and $20 \mathrm{~min}$ gave the best flexural strength and $190^{\circ} \mathrm{C}, 40 \mathrm{rpm}$ and $25 \mathrm{~min}$ for flexural modulus. Conditioning of composite tends to reduce its tensile modulus while increasing its strength and flexural modulus. All samples were produced at only $10 \mathrm{w} \%$ (mass) of fibre in the composite at 1:1 and less than $0.3 \mathrm{~mm}$ fibre ratio and length respectively. Utilization of these parameters according to end requirement can help in achieving optimum mechanical properties on hybridized composites.
\end{abstract}

Keyword: Hybrid; Processing; Mixing; Fibre; Parameters; Reinforced; Conditioned 